\title{
Communications
}

\section{Status of Toxoplasma gondii in the aetiology of senile human cataract}

\author{
P. D. DAVIES, D. G. FLEGK, AND A. H. S. RAHI \\ From Moorfields Eye Hospital, High Holborn, the Public Health Laboratory, St. George's Hospital, \\ London, and The Department of Pathology, Institute of Ophthalmology, University of London
}

Cataract in man is primarily associated with the ageing process and the changes in the lens are widely regarded as corresponding to those of ageing tissue generally-namely, a diminished metabolism and accumulation of waste material, modified by a large number of other factors of a genetic, endocrine, or local nutritional nature (Duke-Elder, 1969).

Until recently, the presence of parasitic micro-organisms in the human lens, and, in particular, the protozoan Toxoplasma gondii, has not been seriously considered as a possible factor in the aetiology of senile cataracts in man, although this is well recognized in other species, such as certain freshwater fish in which trematode cataracts are common (Ashton, Brown, and Easty, I969). The recent work of Ourth (197 ra, b), in which he claimed to have demonstrated $\mathcal{T}$. gondii in 30 per cent. of his series of cataractous human lenses using the direct fluorescent antibody technique (Table I), is therefore of great interest and the purpose of the work described. in this paper has been to re-examine this question and to determine whether Ourth's claim that $T$. gondii plays an aetiological role in human senile cataract could be confirmed.

Table I Data on 43 human cataract patients (after Ourth I97 I $a, b$ )

\begin{tabular}{|c|c|c|c|}
\hline \multirow{2}{*}{$\begin{array}{l}\text { Toxoplasma indirect fluorescent } \\
\text { antibody test } \\
\text { (Serum antibody titres) }\end{array}$} & \multirow{2}{*}{$\begin{array}{l}\text { Toxoplasma in cataracts by } \\
\text { direct fluorescent } \\
\text { antibody test }\end{array}$} & \multicolumn{2}{|c|}{ Patients } \\
\hline & & No. & Per cent. \\
\hline$\geqslant 1: 16$ & Present & 13 & 30 \\
\hline$\geqslant \mathrm{I}: \mathrm{I} 6$ & Absent & I6 & 37 \\
\hline Negative & Absent & 14 & 33 \\
\hline Total & & 43 & 100 \\
\hline
\end{tabular}

\section{Material and method}

Cataractous human lenses removed by the intracapsular method, together with a blood specimen, were obtained from 153 patients at Moorfields Eye Hospital. Their ages varied from 16 to 88 years, $87 \cdot 6$ per cent. ( 134 ) being between 50 and 88 years. In addition, 26 normal lenses were obtained from donor eyes which had been used to provide material for keratoplasty. For obvious reasons it was not possible to obtain a blood specimen from the donors. Each lens was stored in I ml. normal saline containing 33 units sodium penicillin $\mathrm{G}$ and $33 \mu \mathrm{g}$. streptomycin per $\mathrm{ml}$. Those cataractous 
lenses destined for mouse inoculation were stored at $+4^{\circ} \mathrm{C}$. before inoculation within $4^{8} \mathrm{hrs}$ of their removal; the remainder of the cataractous lenses together with all the normal lenses were stored at $-20^{\circ}$ C. pending fluorescent antibody studies.

TOXOPLASMA FLUORESCENT ANTIBODY TEST (TFAT)

The 103 cataractous lenses and the 26 normal lenses were homogenized individually in a teflon tissue homogenizer (TRI-R Instruments) and centrifuged at 200 r.p.m. for Io min. to deposit the debris. The supernate from each was then re-centrifuged at 2,00o r.p.m. for $15 \mathrm{~min}$. and the deposits suspended in phosphate buffered saline (PBS) $\mathrm{pH} 7 \cdot 2$. Smears were made from this suspension on clean glass slides which were allowed to dry in air for a few minutes before fixation in methyl alcohol for Io min. followed by rinsing in PBS. Four separate slides were made from each lens, thus allowing sufficiently thin smears, approximately $30 \times 20 \mathrm{~mm}$., to minimize the possibility of overlooking even one organism.

Fluorescent anti-toxoplasma immune globulin (Wellcome) prepared from the antisera produced in rabbits by repeated injections of Toxoplasma gondii, R.H. strain, was used in this study. Antiserum,

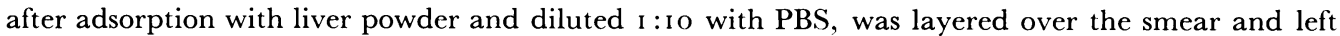
in a moist dark chamber for 30 min., and then washed with three changes of PBS for I hour and mounted with buffered glycerol at $\mathrm{pH} 7 \cdot 2$.

The slides were examined using a Vickers Fluorescent Unit with a U.G. 2 excitor filter, a bright field condenser, and a G.C.4 plus Wratten E barrier filter. Kodak High Speed Ektachrome Film, daylight type (ASA I6o) was used for photomicrography of the prepared slides with an exposure time of 30 to 60 sec. as necessary.

Peritoneal fluid and brain homogenates from mice infected with T. gondii ,R.H. strain, were used as positive controls. These were added to cataractous and normal lenses from patients with negative toxoplasma dye test, homogenized, and processed in exactly the same way as the test material.

Cryostat sections were made of fresh cataractous lenses from patients with both positive and negative dye tests as well as normal human lenses. These sections were processed in a manner similar to that of the test smears.

\section{TOXOPLASMA DYE TESTS}

The toxoplasma dye test (Sabin and Feldman, 1948) was performed at the Public Health Laboratory, St. Georges Hospital, London, S.W. I7, on serum from each of the 153 patients whose cataractous lenses were used in this study. The dye test is regarded as positive by this laboratory when the serum antibody titre is $\geqslant \mathrm{I}: 16$ and interpreted as indicating previous infection with Toxoplasma gondii. A titre of $\mathrm{I}: 256$ may be expected in about $\mathrm{I}$ per cent. of normal adults. In this study, four cases $(2 \cdot 6$ per cent.) had a titre of $\mathrm{I}: 256$, a further four cases a titre of $\mathrm{I}: 5 \mathrm{I} 2$, and two cases $(\mathrm{I} \cdot 3$ per cent) a titre of $\mathrm{I}: \mathrm{I}, 024$. Only a significant rise in titre (four-fold or greater) in suitably paired serum samples is regarded as evidence of current infection.

\section{MOUSE INOGULATION}

A series of fifty cataractous lenses was homogenized with the saline used for their transport until the material was fine enough to be aspirated into a syringe. Equal volumes of this aspirate were injected into three mice from a batch known to be free from toxoplasma infection. The mice were white Swiss strain, approximately $25 \mathrm{~g}$. in weight, and were kept for 6 weeks before they were killed. The brains were removed, emulsified in saline, and examined under a light microscope for T. gondii tissue cysts. Heart blood was removed and the toxoplasma dye test performed on it.

Survival experiments were performed in a similar way, except that dilutions of a suspension of proliferative forms of $T$. gondii, R.H. strain, were added to lenses from patients with both positive and negative dye tests and the preparation kept at $+4^{\circ} \mathrm{C}$. for $4^{8} \mathrm{hrs}$ before inoculation. The R.D.50 of the strain used was found to be less than ten organisms and it was not thought necessary to titrate 
this further as the survival of the organisms in the lens suspension would have been adequate for isolation from the subjects under test.

\section{Results}

The positive controls showed characteristic fluorescence on Toxoplasma Fluorescent Antibody Testing (TFAT) which allowed a positive response to be defined with some precision. The proliferative forms of $T$. gondii were typically of crescentic form, approximately $2 \times 7 \mu$ in size, showing an "apple-green" fluorescence of regular outline with a well-marked hyperfluorescent cap (polar staining) and an area of relative non-fluorescence representing the nucleus (Fig. I, overleaf). The cystic forms of the organism were considerably larger, up to г оo $\mu$ in diameter, and showed similar apple-green fluorescence confined by a. regular and generally circular outline within which numerous encysted organisms could be seen (Fig. 2, overleaf).

Of the 103 cataractous lenses examined for $T$. gondii using TFAT, 56 ( 54 per cent.) had positive dye tests and 47 ( 46 per cent.) negative dye tests. Structures conforming to the above definition of the proliferative and cystic forms of the organism were not found in any of the lenses from either of these two groups (Table II). Fluorescent particles of variable size and shape were seen (Fig. 3, overleaf), but these were regarded as artefacts, since they did not satisfy the above definition for reasons discussed in detail later.

Table II Data on 103 human cataract patients (present study)

\begin{tabular}{|c|c|c|c|}
\hline \multirow{2}{*}{$\begin{array}{l}\text { Toxoplasma dye test } \\
\text { (Serum antibody titres) }\end{array}$} & \multirow{2}{*}{$\begin{array}{l}\text { Toxoplasma in cataracts by } \\
\text { direct fluorescent antibody } \\
\text { test }\end{array}$} & \multicolumn{2}{|c|}{ Patients } \\
\hline & & No. & Per cent. \\
\hline$\geqslant \mathrm{I}: \mathrm{I} 6$ & Absent & $5^{6}$ & 54 \\
\hline Negative & Absent & 47 & 46 \\
\hline Total & & 103 & 100 \\
\hline
\end{tabular}

Mouse inoculation was performed with fifty cataractous lenses, of which 27 (54 per cent.) were from patients with positive dye tests and 23 ( 46 per cent.) from patients with negative dye tests. T. gondii was not isolated from any lens (Table III).

Table III Data on 50 human cataract patients (present study)

\begin{tabular}{|c|c|c|c|}
\hline \multirow{2}{*}{$\begin{array}{l}\text { Toxoplasma dye test } \\
\text { (Serum antibody titre) }\end{array}$} & \multirow{2}{*}{$\begin{array}{l}\text { Toxoplasma in cataracts } \\
\text { by mouse inoculation }\end{array}$} & \multicolumn{2}{|c|}{ Patients } \\
\hline & & No. & Per cent. \\
\hline$\geqslant 1: 16$ & Absent & 27 & 54 \\
\hline Negative & Absent & 23 & 46 \\
\hline Total & & 50 & 100 \\
\hline
\end{tabular}

Cryostat sections of normal and cataractous lenses treated with Fluorescent AntiToxoplasma Reagent (FATR) showed similar patterns of fluorescence which was considerably reduced when the reagent was adsorbed with liver powder. The lens nucleus exhibited a pale autofluorescence, while the anterior epithelium of the lens and its 
immediate cortex showed a brighter, more dense fluorescence of similar colour to that shown by the positive controls. In the case of the cortex and epithelium, however, the fluorescence was of an even, zonal distribution without focal variations (Fig. 4, opposite). Homogenates of a portion of the lenses from which cryostat sections were made showed fluorescent artefacts with the TFAT which were indistinguishable from those seen in variable numbers in smears of every test lens.

\section{Discussion}

One of the problems that arises in using direct immunofluorescent antibody techniques to demonstrate a particular antigen is concerned with the satisfactory exclusion of unwanted fluorescence. This is especially troublesome when working with human lens tissue, which is noted for the frequency with which non-specific fluorescence occurs and which in addition exhibits a considerable auto-fluorescence. Other possible sources of unwanted fluorescence were excluded by centrifuging the conjugate to remove precipitates (Beck, I 97 I) and by confirming the absence of free fluorescein in the conjugate. Even when these precautions are taken, as was done in this investigation, non-specific fluorescence still occurs and may give rise to artefacts. In the smears prepared from lens homogenates, these appear as brightly fluorescent particles (Fig. 3) which we concluded to be artefacts because of the following characteristics:

(i) Unlike the positive controls defined above, their size and shape were variable with an irregular outline and absent polar staining. These characteristics allowed ready differentiation of artefacts from organisms of similar size and general shape.

(ii) The number of these structures was greatly reduced when the antiserum was adsorbed with liver powder. Before adsorption, ten to fifteen were present per smear whereas after adsorption only one or two particles at the most were present and often none at all, suggesting that many of these particles were due to precipitates in the conjugate (Beck, I 97 I).

(iii) There was no significant difference in the number or nature of these particles between cataractous and normal lenses and between cataractous lenses from patients with positive and negative dye tests.

(iv) As described above, cryostat sections of both normal and cataractous lenses showed a non-specific zonal fluorescence in the region of the anterior lens epithelium. Fig. 4 clearly shows small fragments breaking away from this fluorescent zone, several of these particles are of similar size and shape as the proliferative forms of $T$. gondii seen in Fig. I and might easily be confused with the organism.

FIG. I. Direct immunofluorescent staining of proliferative forms of $\mathbf{T}$. gondii, showing their regular crescentic outline and polar staining. Two macrophages containing proliferative forms of the organisms are also seen $. \quad \times 300$

FIG. 2. Direct immunofuorescent staining of cystic forms of $\mathrm{T}$. gondii, illustrating their generally circular outline. $\times 300$

FI G. 3. Artefactual fluorescent particles of variable size and shape (three examples), illustrating their characteristically irregular outline. Direct immunofluorescence technique. $\times 300$

FIG. 4. Cryostat section of a cataractous human lens from a patient with negative toxoplasma dye test. The non-specific fluorescence of the lens capsule and anterior epithelium is arrowed; to the left of this is seen the auto fluorescence of the anterior cortex. $\times 300$ 

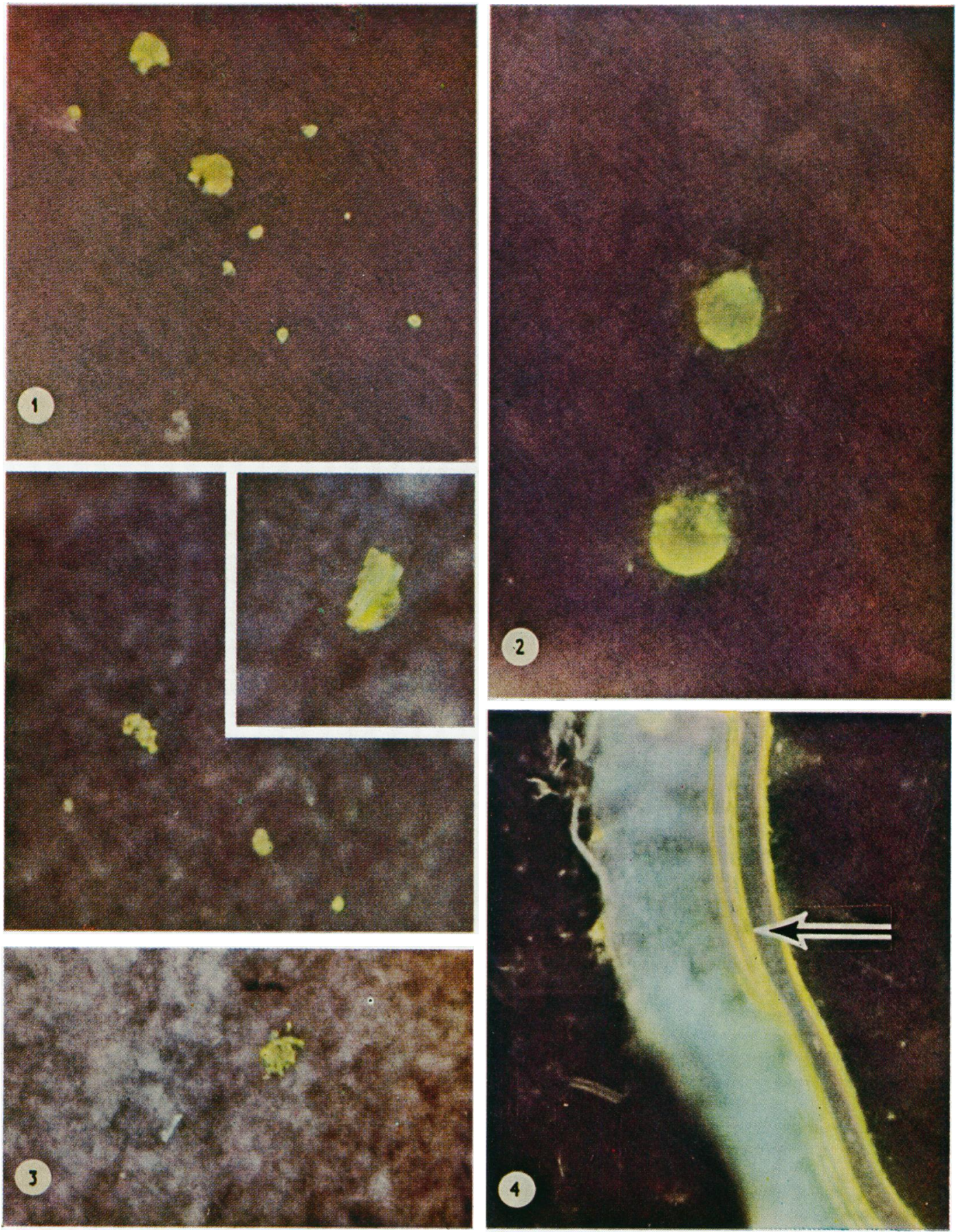

To face page 720 
Although Ourth (I97Ia), in his series, defined his positive controls in a manner similar to that established in this study, there is no indication that he applied this definition rigidly to the cataractous lenses he studied. On the contrary, he states that the form of the particles he designated as toxoplasma organisms "was so irregular that it was not possible to say whether they represented cystic or proliferative forms". He explained the bizarre shape of those structures by assuming them to be organisms disrupted during homogenization of the lenses. It seems probable to us that they were artefacts of similar nature and origin to those described in this investigation; namely fragments of lens epithelium disrupted during homogenization. In order to confirm that significant disruption of toxoplasma organisms does not occur as a result of lens homogenization, we compared smears of lenses to which 25 proliferative forms of $T$. gondii, R. H. strain, were added before and after homogenization. No difference was found between these two groups and in particular no recognizable fragments of disrupted organisms were seen in the preparations to which the organisms had been added before homogenization.

We cannot confirm Ourth's finding of fluorescent particles, considered to be Toxoplasma gondii, only in lenses from patients with positive toxoplasma antibody tests.

\section{Conclusions}

Evidence of Toxoplasma gondii parasites was not found in human cataractous lenses investigated by a direct fluorescent antibody technique and by mouse inoculation. Consequently, we cannot at present regard toxoplasmosis as a significant direct factor in the aetiology of senile human cataracts.

We have great pleasure in acknowledging the guidance given to us in this study by Prof. Norman Ashton, F.R.S. The collection of the cataractous lenses was only made possible by the kind co-operation of the operating theatre staff at Moorfields Eye Hospital, and we should also like to thank Miss G. Munn, Mrs. G. AlKhafaji, and Mrs. M. Perkins for their technical assistance, and Miss B. A. Streek for secretarial help.

\section{References}

AShton, N., BROWn, N., and EASTy, D. (1969) Trans. ophthal. Soc. U.K., 89, 263 BECK, J. s. (197I) “Immunofluorescence Techniques in Immunopathology and Histopathology".

Association of Clinical Pathologists, Broadsheet No. 69. B.M.A., London DUKE-ELDER, s. (1969) “System of Ophthalmology", vol. I I. Kimpton, London OURTH, D. D. (1971a) Brit. F. exp. Path., 52, 276 (197 I b) Immunology, 20, 323, 437

SABIN, A. B., and FELDMAN, H. A. (1948) Science, 108, 660 